\title{
Investigation of Selective Reduction of Iron Oxide in Zinc Ferrite by Carbon and Hydrogen
}

\author{
Mania Kazemi ${ }^{1} \cdot$ Du Sichen ${ }^{1}$
}

Published online: 24 November 2015

(C) The Minerals, Metals \& Materials Society (TMS) 2015

\begin{abstract}
The feasibility of selective reduction of iron oxide in zinc ferrite, which is one of the main components of electric arc furnace dust (EAFD), was examined. Experiments were carried out by using graphite powder or pure hydrogen gas as reducing agents. The carbothermal reduction experiments performed at temperatures between 973 and $1073 \mathrm{~K}$ in inert atmosphere indicated that the method was difficult to apply in practice due to slow rates of reaction and vaporization of zinc. Selective reduction of iron oxide in zinc ferrite was achieved by using pure hydrogen gas as the reductant. The iron oxide was reduced to metallic iron, while $\mathrm{ZnO}$ remained unreacted in the solid phase. As reaction times were increased at $873 \mathrm{~K}, \mathrm{ZnO}$ was also reduced and zinc evaporated. The main advantages of $\mathrm{H}_{2}$ reduction are high reaction rates, low energy requirements, and no $\mathrm{CO}_{2}$ emissions. The addition of this process prior to the hydrometallurgical techniques for treatment of EAFD could overcome the difficulties for dissolution of zinc ferrite.
\end{abstract}

Keywords Zinc ferrite - EAF dust - EAFD recycling . Selective reduction

The contributing editor for this article was S. Kitamura.

Du Sichen

sichen@kth.se

1 Department of Materials Science and Engineering, KTH Royal Institute of Technology, 10044 Stockholm, Sweden

\section{Introduction}

The electric arc furnace dust (EAFD) is classified as hazardous waste due to the presence of leachable toxic elements such as $\mathrm{Pb}, \mathrm{Cd}$, and $\mathrm{Cr}^{6+}$. The environmental and economical aspects have resulted in growing interests in recovery of zinc and iron from the EAF dusts. Several hydrometallurgical and pyrometallurgical processes have been investigated for treatment of EAFD [1]. Application and efficiency of these techniques are greatly influenced by the chemical composition of the dust which depends on the scrap composition, the produced steel grade, and the alloying elements. The preceding reports indicate that the EAF dusts mainly consist of $\mathrm{ZnO}, \mathrm{Fe}_{3} \mathrm{O}_{4}, \mathrm{PbO}$, and $\mathrm{ZnFe}_{2} \mathrm{O}_{4}$ oxide phases [2-4].

The hydrometallurgical methods for recycling EAFD include various leaching and extraction steps [1]. The Ezinex and the modified Zincex processes are implemented in industrial scale for treatment of dusts with low zinc ferrite contents [5, 6]. Despite low energy consumption, high efficiency, and low content of impurities in the products, application of the hydrometallurgical procedures is limited by the complications involved in leaching of zinc ferrite. Thus, several works have focused on optimization of leaching conditions for $\mathrm{ZnFe}_{2} \mathrm{O}_{4}$ and using methods such as pressure leaching and high-temperature leaching [5-8].

The high-temperature processes for EAFD treatment involve reduction of zinc and iron oxides by carbonaceous reducing agents at temperatures above $1373 \mathrm{~K}$. These processes require high energy consumption and increase the $\mathrm{CO}_{2}$ production [1]. The Waelz kiln process is widely used for recycling of EAF dust. However, new reduction processes have been examined and proved to be effective in treatment of EAFD and obtaining products with lower impurities than the Waelz kiln process [9-13]. 
Since the main obstacle in EAFD leaching is dissolution of zinc ferrite, separation and reduction of zinc oxide and iron oxide in $\mathrm{ZnFe}_{2} \mathrm{O}_{4}$ can be employed as a primary step to prepare the dust for hydrometallurgical processing. Application of reduction conditions at which zinc oxide is more stable than iron oxide would result in a product containing metallic iron and $\mathrm{ZnO}$, which can be processed by hydrometallurgical methods for recovery of both metals. Ye et al. applied different forms of carbon for selective reduction of iron oxide in EAFD and reported that the process is feasible at $1073 \mathrm{~K}$ [14].

The purpose of the present work is to investigate the selective reduction of iron oxide in zinc ferrite. Graphite powder and hydrogen gas are used as reducing agents. The experiments are conducted with well-controlled atmosphere and temperature profile. The experimental setup facilitates performing isothermal solid-solid reactions and prevents the reaction to start before reaching the desired temperature and gas atmosphere.

\section{Materials and Methods}

\section{Materials Preparation}

The samples for carbothermal reduction experiments were made of $2 \mathrm{~g}$ of $\mathrm{ZnFe}_{2} \mathrm{O}_{4}$ and $0.3 \mathrm{~g}$ of fine graphite powder, both supplied by Alfa Aesar. The powders were fully mixed in an agate mortar and the mixture was pressed into disks under $10 \mathrm{MPa}$ pressure in a laboratory-scale hydraulic press. The disks had $14 \mathrm{~mm}$ diameter and $5 \mathrm{~mm}$ thickness. The samples for gaseous reduction tests were prepared by pressing $2 \mathrm{~g}$ of $\mathrm{ZnFe}_{2} \mathrm{O}_{4}$ powder into disks. Few samples containing mixtures of hematite and zinc oxide were tested under similar conditions applied for hydrogen reduction of zinc ferrite. The pure hematite and zinc oxide powders were provided by Fisher Scientific and Alfa Aesar, respectively.

\section{Experimental Procedure}

All experiments were carried out isothermally in the apparatus illustrated in Fig. 1. The details of the setup can be found in a previous publication [15]. The reduction tests were conducted according to the following procedures. The sample was placed in an alumina holder, which was connected to the balance by a wire. The setup was closed and completely sealed. High-purity argon (99.9995\%) with $1 \mathrm{~L} \mathrm{~min}^{-1}$ flow rate was passed through the system. Thereafter heating was started. The sample was kept in the water-cooled chamber at room temperature during heating. The balance was protected by a constant flow of Ar gas

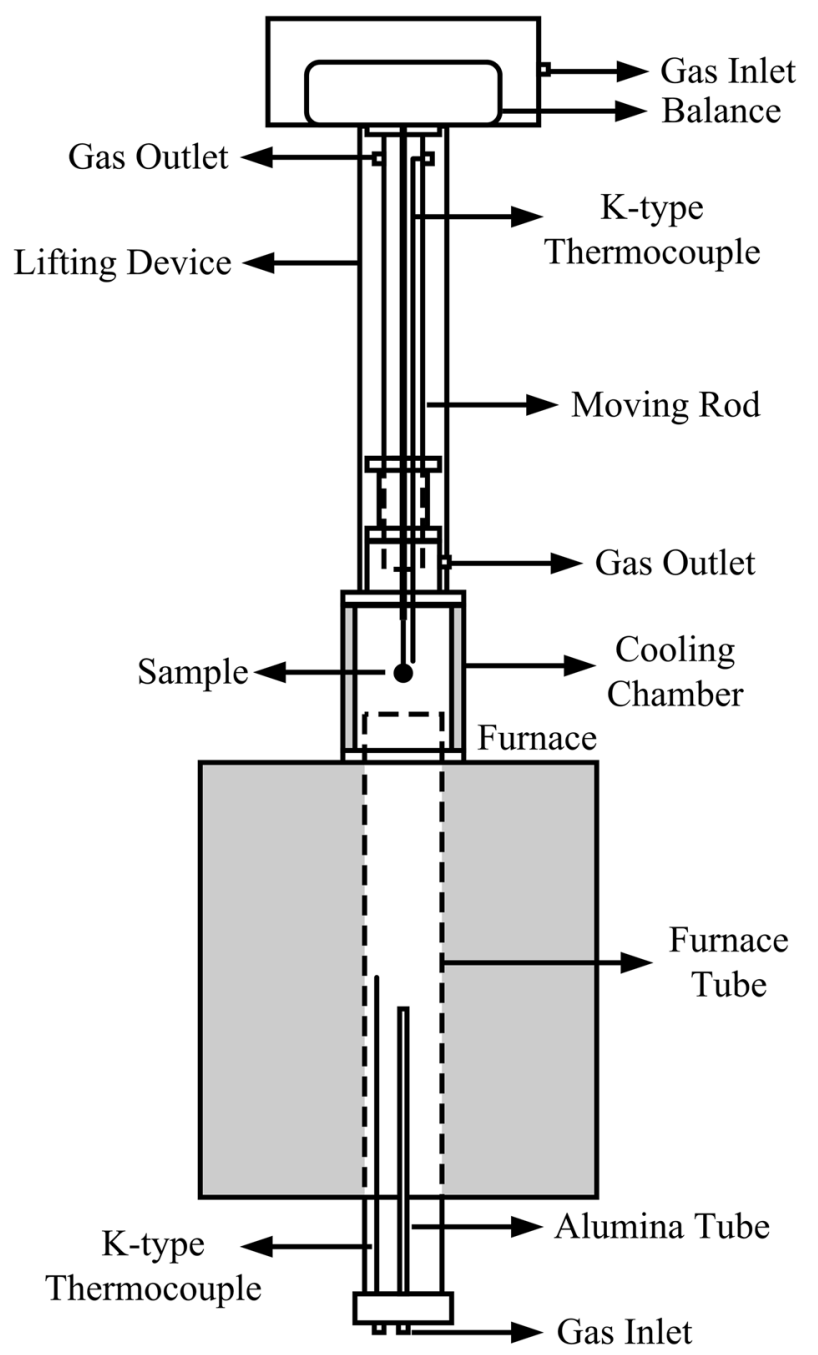

Fig. 1 Schematic illustration of experimental setup [15]

with low flow rate during the experiments. All the gas flow rates were controlled by mass flow meters.

In a typical carbothermal reduction experiment, Ar flow rate was fixed to $0.2 \mathrm{~L} \mathrm{~min}^{-1}$ and the sample was rapidly lowered from the cooling chamber to the hot zone, when the experimental temperature in the hot zone was reached and stabilized.

In the gaseous reduction experiments, after reaching the target temperature the furnace tube was flushed by pure hydrogen gas (99.9995\% pure) with a fixed flow rate. After $10 \mathrm{~min}$, when the hydrogen concentration became homogeneous and $1 \mathrm{~atm}$. in the reaction chamber, the sample was moved to the hot zone and the reaction was started.

In all experiments, the sample weight was recorded by the balance. When the weight change became negligible, the sample was quenched by lifting it to the cooling chamber and passing argon gas with high flow rate. The 
movement of the sample to and from the hot zone was done rapidly and the sample reached temperatures below $373 \mathrm{~K}$ in less than $40 \mathrm{~s}$.

All the phase analyses were performed using the X-ray diffraction technique (XRD) and scanning electron microscopy (SEM) equipped with energy-dispersive X-ray spectroscopy (EDS).

\section{Results}

\section{Carbothermal Reduction of Zinc Ferrite}

The carbothermal reduction of zinc ferrite in inert atmosphere was investigated at three different temperatures. Equation 1 shows the reaction between $\mathrm{ZnFe}_{2} \mathrm{O}_{4}$ and graphite when iron oxide is selectively reduced to iron, while $\mathrm{ZnO}$ remains unreacted.

$\mathrm{ZnFe}_{2} \mathrm{O}_{4}+3 \mathrm{C}=\mathrm{ZnO}+2 \mathrm{Fe}+3 \mathrm{CO}$

The tests were performed isothermally at 973, 1023, and $1073 \mathrm{~K}$ in pure argon atmosphere. The curves representing the weight change versus time are illustrated in Fig. 2. The plots show the slow rate of reaction between $\mathrm{ZnFe}_{2} \mathrm{O}_{4}$ and graphite, especially at 973 and $1023 \mathrm{~K}$. Analysis of the samples reacted for $6 \mathrm{~h}$ revealed that at 973 and $1023 \mathrm{~K}$ the samples consisted of $\mathrm{ZnFe}_{2} \mathrm{O}_{4}, \mathrm{FeO}, \mathrm{ZnO}$, and graphite. After reduction at $1073 \mathrm{~K}$, the only phases that remained in the sample were $\mathrm{FeO}$ and graphite. At this temperature, $\mathrm{ZnO}$ was completely reduced and $\mathrm{Zn}$ was evaporated. The present outcomes are in contradiction with the published data [14]. Note that the purpose of this work is selective reduction of iron oxide from zinc ferrite without reducing the zinc oxide. Using large amounts of carbon is not favorable for economic and environmental reasons.

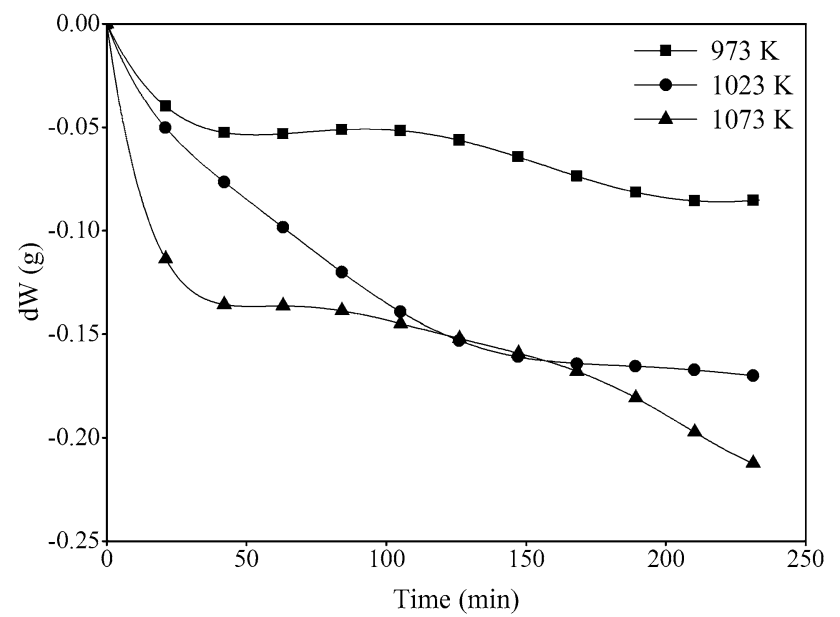

Fig. 2 Weight change during reduction of $\mathrm{ZnFe}_{2} \mathrm{O}_{4}$ by graphite in argon atmosphere
Additionally, if carbon remains in the product, the recycling process requires another step for removal of carbon. Therefore, the amount of graphite used in the samples is close to the stoichiometric ratio for reducing the iron oxide in the sample to metallic iron.

\section{Gaseous Reduction of Zinc Ferrite by $\mathbf{H}_{2}$}

High temperatures and long reaction times required for carbothermal reduction of zinc ferrite have raised the interests in investigation of gaseous reduction techniques for processing EAFD. Several researchers have suggested application of gaseous reducing agents for treatment of EAF dusts [10-13, 16]. In this work, the isothermal reduction of zinc ferrite by hydrogen gas was examined. The reduction of iron oxide by hydrogen can be carried out at lower temperatures compared to reduction by carbon. The rate of solid-gas reaction is much higher than the solid-solid reaction between the oxide and carbon. Therefore, pure hydrogen gas was used for reduction at temperatures between 623 and $873 \mathrm{~K}$.

The selective reduction of zinc ferrite by hydrogen is expected to take place through the following reaction:

$\mathrm{ZnFe}_{2} \mathrm{O}_{4}+3 \mathrm{H}_{2}=\mathrm{ZnO}+2 \mathrm{Fe}+3 \mathrm{H}_{2} \mathrm{O}$

When the mixture of oxides is reduced the following reactions occur:

$\mathrm{Fe}_{2} \mathrm{O}_{3}+3 \mathrm{H}_{2}=2 \mathrm{Fe}+3 \mathrm{H}_{2} \mathrm{O}$

$\mathrm{ZnO}+\mathrm{H}_{2}=\mathrm{Zn}+\mathrm{H}_{2} \mathrm{O}$

Figure 3 depicts the extents of reaction $(f)$ versus time at different temperatures. The extent of reaction is defined by Eq. 5.

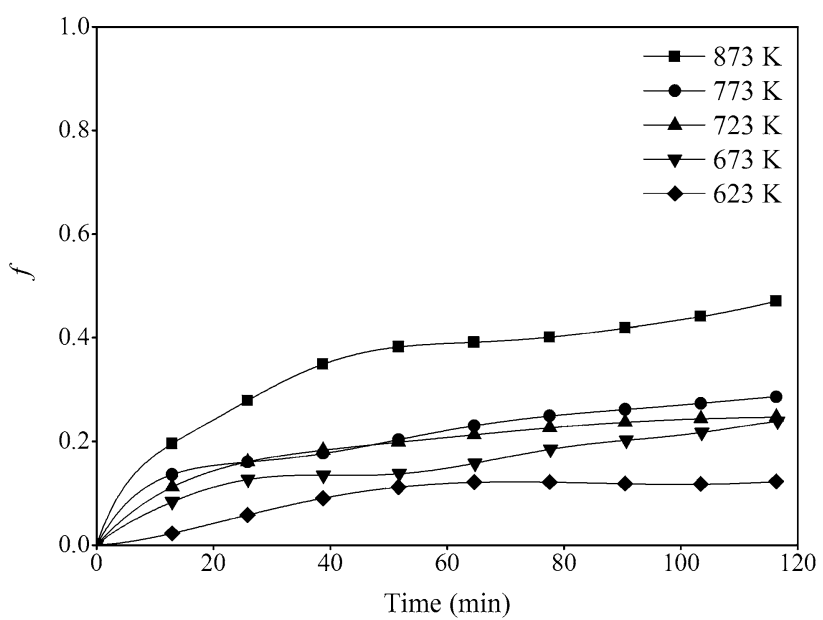

Fig. 3 Effect of temperature on reduction of $\mathrm{ZnFe}_{2} \mathrm{O}_{4}$ by $\mathrm{H}_{2}$, $Q_{\mathrm{H} 2}=1 \mathrm{~L} \mathrm{~min}{ }^{-1}, f$ is defined as the extend of reaction, see Eq. 5 
$f=\frac{W_{0}-W_{t}}{\Delta W_{\text {total }}}$

In Eq. $5, W_{0}$ is the initial weight of sample, $W_{t}$ is the weight of sample at time $t$, and $\Delta W_{\text {total }}$ is the total weight change if both zinc oxide and iron oxide in the sample are completely reduced and zinc is evaporated from the sample.

The effect of gas flow rate on reduction rate was examined by using different flow rates, namely $1,1.5$, and $2 \mathrm{~L} \mathrm{~min}^{-1}$ at $773 \mathrm{~K}$. In the initial $5 \mathrm{~min}$, the reaction took place with similar rates. At later stages, the rate was slightly higher at higher gas flow rates (1.5 and $2 \mathrm{~L} \mathrm{~min}^{-1}$ ). For the rest of the gaseous reduction experiments, fixed $\mathrm{H}_{2}$ flow rate equal to $1 \mathrm{~L} \cdot \mathrm{min}^{-1}$ was used.

It is observed in Fig. 3 that the initial rate of reaction is higher at higher temperatures. After approximately $5 \mathrm{~min}$, the rates decrease at all temperatures and the reaction continues until the variation in weight becomes negligible. The extent of reaction corresponding to the total reduction of iron oxide in zinc ferrite is equal to 0.37. Accordingly, the curves reaching reaction extents higher than 0.37 are a clear indication of reduction of both $\mathrm{Fe}_{2} \mathrm{O}_{3}$ and $\mathrm{ZnO}$. At $873 \mathrm{~K}$, the sample reacted for $2 \mathrm{~h}$ reached reaction extents around 0.5 , and $\mathrm{ZnO}$ was also reduced.

The phases in the samples reacted for $2 \mathrm{~h}$ were identified by X-ray diffraction. The investigation of chemical composition of the phases by SEM-EDS was in agreement with the XRD data. The results showed that these samples had varying contents of $\mathrm{Fe}, \mathrm{FeO}$, and $\mathrm{ZnO}$. The amount of $\mathrm{ZnO}$ was higher in the samples reduced at lower temperatures. On the other hand, higher temperatures enhanced the reduction of $\mathrm{FeO}$ to $\mathrm{Fe}$, and at $873 \mathrm{~K}$ iron oxide was completely reduced to iron. Therefore, few samples were quenched at four time intervals during reduction at $873 \mathrm{~K}$. Analysis of the phases illustrated that the iron content was increased at longer reaction times. After $40 \mathrm{~min}, \mathrm{FeO}$ was fully reduced to $\mathrm{Fe}$ and the decrease in the $\mathrm{ZnO}$ content was negligible. Figure 4 presents the $\mathrm{X}$-ray diffraction pattern from the sample reduced for $40 \mathrm{~min}$. The presence of $\mathrm{Fe}$ and $\mathrm{ZnO}$ phases is evidently seen in this figure. Further reaction at $873 \mathrm{~K}$ was followed by reduction of $\mathrm{ZnO}$ and evaporation of $\mathrm{Zn}$.

\section{Discussion}

\section{Reduction of $\mathrm{ZnFe}_{2} \mathrm{O}_{4}$ by Graphite Powder}

The curves in Fig. 2 show the significant influence of temperature on rate of carbothermal reduction. Slow reaction rates at low temperatures, substantial reduction of $\mathrm{ZnO}$, and loss of zinc at higher temperatures are observed

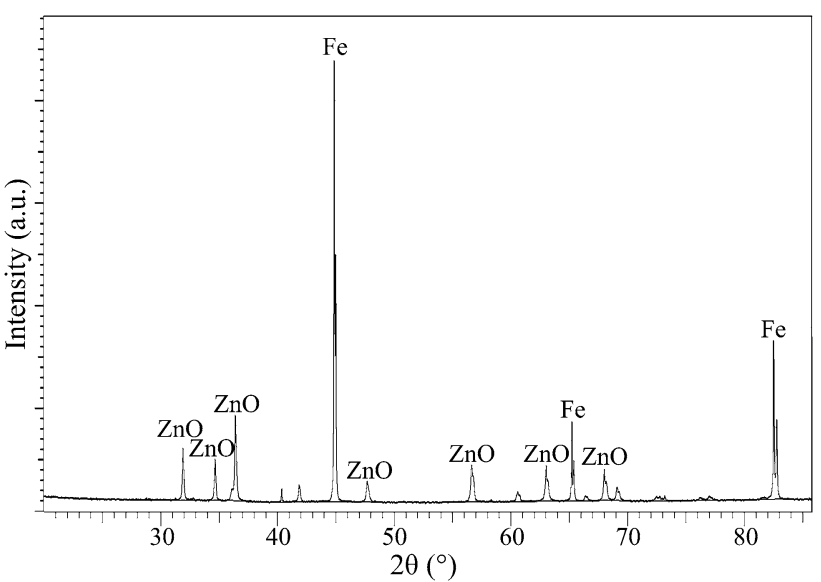

Fig. 4 XRD pattern from the sample reduced at $873 \mathrm{~K}$ for $40 \mathrm{~min}$ by $\mathrm{H}_{2}, Q_{\mathrm{H} 2}=1 \mathrm{~L} \mathrm{~min}^{-1}$

at temperatures between 973 and $1073 \mathrm{~K}$. It can be seen that the weight increases slightly between 50 and $100 \mathrm{~min}$ at $973 \mathrm{~K}$. This could be due to the carbon deposition on the suspending wire at lower temperature zone.

Microscopic image of the zinc ferrite-graphite sample (Fig. 5) depicts that the graphite particles have smaller size than the zinc ferrite powder. The surface contact between the particles is a rate-limiting factor in solid-solid reaction. Limited surface contact between the reacting particles strengthens the effect of solid-state diffusion on the rate and decreases the total rate of reduction. Application of finer zinc ferrite powder and larger amounts of graphite can enhance the reaction rate. The total rate is also influenced by the mass transfer of the gaseous products from the reaction sites. The produced $\mathrm{CO}$ diffuses through the solid phase to the surface of the sample and is carried away from the surface by the argon stream. The rates of mass transfer in the solid phase and the gas phase affect the concentrations of reductant and product gases and change the reaction rate by shifting the local equilibrium in backward and forward directions (Eq. 1). It can be expected that reduction of $\mathrm{ZnO}$ and vaporization of $\mathrm{Zn}$ in experiments (e.g., at

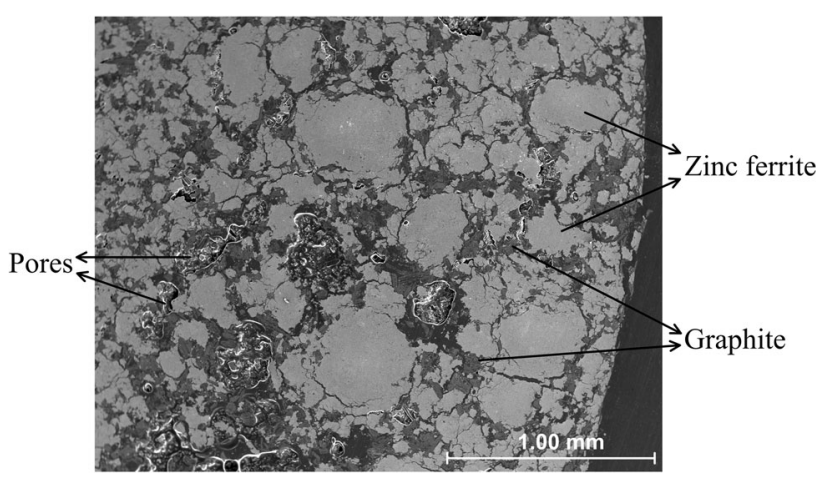

Fig. $5 \mathrm{SEM}$ microphotograph of $\mathrm{ZnFe}_{2} \mathrm{O}_{4}$-graphite sample 
$1073 \mathrm{~K}$ ) increases the sample porosity. Hence, the external mass transfer can be a significant factor in the rate control.

Investigation of the reduction products illustrated that at the applied conditions the iron oxide was reduced to $\mathrm{FeO}$ without further reduction to metallic iron even after long reaction times. At $1073 \mathrm{~K}, \mathrm{ZnO}$ was completely reduced and zinc evaporated from the sample. These findings are in contradiction with the results reported by Ye et al. [14]. When they applied anthracite as the reductant, zinc ferrite was reduced to metallic iron and zinc oxide. They found very low amounts of zinc in the gas phase when reduction was performed at $1073 \mathrm{~K}$ [14]. Although it is well known that $\mathrm{FeO}$ can be reduced to $\mathrm{Fe}$ by carbon, the experimental results and analysis of the samples evidently show that despite the presence of graphite in the samples, the reduction of $\mathrm{FeO}$ to $\mathrm{Fe}$ at the applied conditions is not substantial. This can be attributed to the slow rate of reduction by graphite.

Thermodynamic calculation could be helpful to explain the results. However, due to the unknown kinetic parameters in the system, it is difficult to estimate the partial pressures of the gaseous species, $\mathrm{H}_{2} \mathrm{O}$, and $\mathrm{Zn}$ (gas). Further study is needed to obtain these data for making a reliable thermodynamic calculation.

\section{Reduction of $\mathrm{ZnFe}_{2} \mathrm{O}_{4}$ by Hydrogen Gas}

Variation of $\mathrm{H}_{2}$ flow rates at $773 \mathrm{~K}$ had no significant effect on the initial rate of reaction. In the beginning of reaction, the outer surface of the samples is exposed to the gas stream with homogeneous reducing potential and the reaction is fast. At later stages, the gaseous diffusion and concentration of hydrogen in the inner parts of the samples become influential in controlling the total rate. Higher $\mathrm{H}_{2}$ flow rates increase the reducing potential of the gas and diffusion rate of hydrogen, and thus, the reaction rate was higher at 1.5 and $2 \mathrm{~L} \mathrm{~min}^{-1}$ flow rate.

Figure 3 illustrates the extents of reaction for reduction of $\mathrm{ZnFe}_{2} \mathrm{O}_{4}$ by $1 \mathrm{~L} \mathrm{~min}^{-1}$ hydrogen flow rate at different temperatures. Reduction was faster at higher temperatures at all stages of reaction. Increasing the temperature enhances the rate of chemical reaction and diffusion and therefore improves the total rate of reaction. The reaction rate decreased after the initial period, and at temperatures below $773 \mathrm{~K}$, the sample weight became stable after approximately $120 \mathrm{~min}$. At $873 \mathrm{~K}$, high reaction extent and higher rate were obtained, indicating that both iron oxide and zinc oxide were being reduced.

As mentioned previously, the samples reduced at temperatures between 623 and $873 \mathrm{~K}$ contained $\mathrm{ZnO}, \mathrm{FeO}$, and Fe. Higher amounts of iron were identified at higher temperatures. Reduction of iron oxide started from the initial stages of reaction and Fe was identified in the samples even after 20 min of reaction. The influence of reaction time on the existing phases was examined at $873 \mathrm{~K}$. After $30 \mathrm{~min}$ reduction $\mathrm{Fe}, \mathrm{FeO}$ and $\mathrm{ZnO}$ were identified in the sample. The iron oxide was reduced to iron and zinc oxide remained unreacted after 40 min reaction at $873 \mathrm{~K}$. When the time was increased to $60 \mathrm{~min}, \mathrm{ZnO}$ was reduced. The sample containing mixture of $\mathrm{Fe}_{2} \mathrm{O}_{3}$ and $\mathrm{ZnO}$ was reduced at $873 \mathrm{~K}$ for $2 \mathrm{~h}$. The product contained $\mathrm{Fe}$ and small amounts of $\mathrm{ZnO}$. Accordingly, $\mathrm{H}_{2}$ reduction at temperatures around $873 \mathrm{~K}$ can be used for processing of EAF dusts containing free iron oxide and zinc oxide phases.

These results are similar to the findings in earlier works $[10,13,16]$. Siqueira et al. found metallic iron at the initial stages of reduction of synthesized zinc ferrite samples by $\mathrm{H}_{2}$ at $973 \mathrm{~K}$, although eventually $\mathrm{ZnO}$ was also reduced at this temperature [10]. In an investigation by Polsilapa et al., iron and zinc oxide were present in the samples reduced by pure hydrogen at 773 and $873 \mathrm{~K}$ for $50 \mathrm{~min}$. At temperatures above $973 \mathrm{~K}$, considerable reduction of zinc took place [13].

It should be mentioned that when the dusts from steel plants are to be processed, the reaction rate and mechanism are affected by the presence of other oxides. Tong and Hayes performed a detailed study on the influence of impurity oxides on mechanism of zinc ferrite reduction by hydrogen and concluded that the addition of different oxides impacts the reduction rate and the morphology of the products [16].

Reduction of iron oxide in zinc ferrite by hydrogen is a potential method to eliminate the limitations for dissolution of zinc ferrite in hydrometallurgical processes for recycling of EAFD. Other remarkable characteristics of this process are low reaction temperatures, high reaction rates, and no production of $\mathrm{CO}_{2}$. Considering the differences in structures and chemical compositions of steelmaking dusts, application of this method for treatment of EAFD requires optimization of the process parameters.

\section{Conclusions}

Isothermal reduction of zinc ferrite by fine graphite powder demonstrated that reduction of iron oxide to iron is not achievable at temperatures between 973 and $1073 \mathrm{~K}$. The slow rate of reaction, reduction of $\mathrm{ZnO}$, and large losses of zinc at the applied conditions make the suggested process inefficient for treatment of EAFD.

Selective reduction of iron oxide to iron by pure hydrogen gas was accomplished through reaction at $873 \mathrm{~K}$ for 40 min with negligible reduction of zinc oxide and loss of zinc. This work illustrated that reduction by hydrogen can be an economically beneficial method for recycling of EAF dusts which contain considerable amounts of 
$\mathrm{ZnFe}_{2} \mathrm{O}_{4}$. By performing this step before hydrometallurgical processing of EAFD, the complications involved in leaching of zinc ferrite spinel can be avoided. However, further investigation on the process conditions, such as temperatures, gas flow rate, and the reaction time is needed to develop an environmentally friendly process in larger scale.

\section{References}

1. Nyirenda RL (1991) The processing of steelmaking flue-dust: a review. Miner Eng 4:1003-1025. doi:10.1016/0892-6875(91)90080-F

2. Machado JGMS, Brehm FA, Moraes CAM, Santos CA, Vilela ACF, Cunha JBM (2006) Chemical, physical, structural and morphological characterization of the electric arc furnace dust. J Hazard Mater B 136:953-960. doi:10.1016/j.jhazmat.2006.01. 044

3. Mantovani MC, Takano C, Büchler PM (2004) EAF and secondary dust characterisation. Ironmak Steelmak 31(4):325-332. doi:10.1179/030192304225018163

4. Silva MC, Bernardes AM, Bergmann CP, Tenório JAS, Espinosa DCR (2008) Characterisation of electric arc furnace dust generated during plain carbon steel production. Ironmak Steelmak 35(4):315-320. doi:10.1179/030192307X232936

5. Olper M, Maccagni M (2000) Electrolytic zinc production from crude zinc oxides with the Ezinex ${ }^{\circledR}$ process. In: Stewart DL, Daley JC, Stephens RL (eds) Recycling of metals and engineered materials. Wiley, Hoboken, pp 379-396. doi:10.1002/9781118788073. $\operatorname{ch} 33$

6. Diaz G, Martin D (1994) Modified Zincex process: the clean, safe and profitable solution to the zinc secondaries treatment. Resour Conserv Recycl 10:43-57. doi:10.1016/0921-3449(94)90037-X
7. Leclerc N, Meux E, Lecuire JM (2003) Hydrometallurgical extraction of zinc from zinc ferrites. Hydrometallurgy 70:175-183. doi:10.1016/S0304-386X(03)00079-3

8. Montenegro V, Oustadakis P, Tsakiridis PE, Agatzini-Leonardou S (2013) Hydrometallurgical treatment of steelmaking electric arc furnace dusts (EAFD). Metall Mater Trans B 44:1058-1069. doi:10.1007/s11663-013-9874-0

9. Rösler G, Pichler C, Antrekowitsch J, Wegscheider S (2014) "2sDR": process development of a sustainable way to recycle steel mill dusts in the 21st century. JOM 66(9):1721-1729. doi:10.1007/s11837-014-1131-8

10. Siqueira RNC, Brocchi EA, Oliveira PF, Motta MS (2014) Hydrogen reduction of zinc and iron oxides containing mixtures. Metall Mater Trans B 45(1):66-75. doi:10.1007/s11663-0139951-4

11. Wu CC, Chang FC, Chen WS, Tsai MS, Wang YN (2014) Reduction behaviour of zinc ferrite in EAF-dust recycling with CO gas as a reducing agent. J Environ Manag 143:208-213. doi:10.1016/j.jenvman.2014.04.005

12. Gao JT, Li SQ, Zhang YL, Zhang YT, Chen PY (2012) Experimental study on solid state recovery of metallic resources from EAF dust. Ironmak Steelmak 39(6):446-453. doi:10.1179/ 1743281211Y.0000000093

13. Polsilapa S, Sadedin DR, Wangyao P (2011) Thermodynamics analysis for the zinc ferrite reduction by hydrogen. High Temp Mater Process (Lond) 30:587-592. doi:10.1515/HTMP.2011.119

14. Ye G, Burstrom E, Maccagni M, Bianco L, Stripple H (2006) Elimination of zinc ferrite for hydrometallurgical recovery of zinc from EAF dust. Advanced Processing of Metals and Materials, vol 6. Warrendale, PA, TMS, pp 397-411

15. Kazemi M, Glaser B, Sichen D (2014) Study on direct reduction of hematite pellets using a new TG setup. Steel Res Int 85(4):718-728. doi:10.1002/srin.201300197

16. Tong LF, Hayes P (2007) Mechanisms of the reduction of zinc ferrites in $\mathrm{H}_{2} / \mathrm{N}_{2}$ gas mixtures. Min Process Extract Metall Rev 28(2):127-157. doi:10.1080/08827500601012878 